\title{
USING THE ANALYTIC NETWORK PROCESS (ANP) FOR RANKING THE CRITICAL ISSUES OF A TRANSPORT DECISION PROBLEM: THE ITALIAN SECTION OF THE CORRIDOR 24
}

\author{
Francesca Abastante \\ Department of Housing and City (DICAS) \\ Politecnico di Torino \\ E-mail: franscesca.abastante@polito.it \\ Marta Bottero \\ Department of Housing and City (DICAS) \\ Politecnico di Torino \\ E-mail: marta.bottero@polito.it \\ Isabella M. Lami* \\ Department of Housing and City (DICAS) \\ Politecnico di Torino \\ E-mail: isabella.lami@polito.it
}

\begin{abstract}
The construction of European transport infrastructures can be seen as a complex topic, where different objectives and values have to be taken into account. With specific reference to the trans-European railway axis from Rotterdam to Genoa (i.e. Corridor 24), the presents paper proposes the application of the ANP technique for supporting the decision-making process related to the project for the implementation of the corridor in Italy. In particular, the objective of the work is to rank the effects that the delay in the construction of the Italian portion of the corridor would determine on the territorial system. The full range of effects has been identified and grouped into three clusters (namely, socio-economic aspects, environmental aspects and transport aspects). The model includes both subjective and objective elements, which also have some interdependencies. The complexity of the case under examination compelled for the implementation of the model of an iterative experts consultation, that has been managed through a specific focus group and different questionnaires. The results of the application put in evidence the most important aspects of the decision problem.
\end{abstract}

Keywords: Analytic Network Process, transport infrastructures, evaluation.

\section{Introduction}

The trans-European railway axis (TEN-T) no. 24 from Rotterdam to Genoa (i.e. Corridor 24) covers a number of the most important economic regions in Europe. Crossing the Netherlands, Germany, Switzerland and Italy, this European North-South transport axis is linking the North Sea port of Rotterdam and the Mediterranean port of Genoa. European Union's objective is to double by 2020 the capacity of rail transport on the axle in order to encourage a modal shift of freight by rail: the main projects referring to this topic are the Swiss rail tunnel Loetschberg (opened in 2007), the Gotthard tunnel

\footnotetext{
${ }^{*}$ Corresponding author
} 
(the last wall was torn down in October 2010 and the tunnel will be operational by 2017) and Mount Ceneri tunnel (which is expected in 2020).

Despite of the importance of this connection, not only from the point of view of the freight traffic but also from the point of view of the passengers transport, there are still many problems, both in terms of infrastructure (as many sections do not have adequate capacity of functioning in the corridor), and with reference to the standpoint of management, due to the presence of different transport services (freight, long distance, local traffic) and the lack of coordination and interoperability of trans-regional level. Some major bottlenecks, a lack of trans-regional coordination, a less and less consent among the involved population and the increasing difficulties because of the redoubts financial resources still threaten the potential of the axis, limiting its economic and spatial development.

In particular, the Italian situation is worrying: Italy is late in the implementation of the corridor with respect to the rest of Europe. The European routes works shall be finished at the latest in 2020 but in Italy also the projects that have already obtained a financial support risk not to be completed by that dead line.

The old and poor connection between the port of Genoa, the Lombardy Region and the Swiss border is leading to manage the transport of goods using the road network, with evident environmental and territorial problems.

Removing existing bottlenecks requires co-operation across political, organisational and technical bodies. In areas of conflicts regarding local planning competences and the over - regional spatial planning issues, extensive forms of collaboration together with the use of evaluation techniques able to support the decision-making process have to be explored and tested.

The construction of European transport infrastructures can be seen as a complex topic, where new values have to be taken into account. It is not a specific question of localisms, nor is it merely an issue of moving goods and people, nor does it affect only environmental, transport-related or town planning aspects. Tackling the issue of large-scale infrastructures involves dealing with a maze of decision elements which require new trans-disciplinary approaches. Nowadays, the fundamental issue connected to large-scale infrastructures seems to be related to the definition of the underlying agreements, rather than to the construction itself (Lami and Staffelbach 2008; Bertolini, 2001).

In this context, a very useful support in the decision-making process could be granted by the Analytic Network Process (ANP, Saaty, 2005; Saaty and Vargas, 2006), which allows the different elements (both tangible and intangible) of the problem to be represented according to a network model and the judgements of experts as well as existing measurements and statistics to be considered in the analysis.

In territorial transformation processes (characterized by a long term nature), where different actors are associated in a dynamic context, some indefinite spaces are left that will be negotiated according to future evaluations and an attempt is made to mediate between opposing positions that can change during the decision process. Through the use of the ANP, it becomes possible to compare different objectives, interconnected between them and with different units of measure; furthermore, the analysis makes it possible to identify new definitions of the problem (Bottero, Lami and Lombardi, 2008).

The presents paper proposes the application of the ANP technique for supporting the decision-making process related to the critical issues that could arise from a significant delay in the implementation of the Italian section of Corridor 24. The starting point of the ANP application is the idea that the possibility of not having properly upgraded the Italian railway lines when the Swiss tunnel Gotthard and Mount Ceneri will be working would bring the railway system in Piedmont and Lombardy to the rapid saturation, and the Ligurian ports to lose competitiveness in Europe. In particular, the lack of a functional link between the port of Genoa and the railway network in the hinterland could relegate the Ligurian port to a marginal role with respect to the major ports of Northern Europe, which are organizing an efficient rail connection with their hinterland.

In order to investigate this situation, this paper proposes to use the ANP not to compare different alternatives, but to examine and compare the main aspects of the problem, and to rank it. It is an unusual use of the technique, particularly efficient in case of lack of exhaustive transformation scenarios and, at the same time, in presence of detailed information on key aspects of the decision problem. This 
application of the ANP is part of an Interreg IVB NEW Project, called "Code24", involving 15 partners from 5 Countries for 4 years $(2010-2013)$.

After the introduction, the rest of the paper is organized as follows. Section 2 illustrates the application to the case study, describing the particular use of the ANP technique, the structuring of the decision network, the development of the model and the results. Sections 3 concludes the paper with a discussion and various proposals for improving the method.

\section{Application}

\subsection{The ANP-based approach}

Territorial transformation processes refer to a multidimensional concept that includes socio-economic, ecological, and technical perspectives and thus leads to issues that are simultaneously characterized by a high degree of conflict, complexity and uncertainty. Particularly, when speaking about transport planning, many objectives have to be considered in the decision making process: factors that range from the rationalization of the mobility system to the reduction of soil consumption, from the promotion of economic activities to the cut of air pollution due to traffic emissions, from the endorsement of energy efficiency to the increase in the quality of public spaces.

The assessment of alternative scenarios of transport planning is therefore a complex decision problem where different aspects need to be considered simultaneously, taking into account both technical elements, which are based on empirical observations, and non technical elements, which are based on social visions, preferences and feelings. In this context, a very useful aid is provided by the method of the ANP, which allows the different elements of the decision problem to be represented, considering also their interdependence relationships. The network structure of ANP makes it possible to model various aspects at stake without concern about what comes first and what comes next. This way of representing the problem, with less constrains than the structure imposed by the AHP, is more similar to real situations where the elements act in a non-hierarchical way.

This aspect is particularly important in the application of the ANP proposed in this paper. The ANP is not used as a method to determine a priority list of the different alternatives in the decision problem, but as a structured procedure that is able to support the analysis in the identification of the principal aspects to consider in order to come to a decision (Bottero and Lami, 2010).

In the present study the ANP model has not been applied with the aim of ranking different options in the context of the development of the Corridor 24; the overall object of the analysis is rather to rank the effects that the delay in the construction of the Italian portion of the corridor will determine on the territorial system. In this sense, the ANP consists of a simple network where the different elements and their reciprocal relationships are represented and linked with the aforementioned goal (Nekhay et al., 2009). Mention should be made to the fact that the model has been developed by means of a specific focus group where experts in the different subjects worked together in the compilation of the pairwise comparison matrices. Particularly, the focus group considers different experts in the fields of transport infrastructures, environmental assessment, urban planning, economic evaluation and social sciences. Most of the experts was involved in the "Code24" European Project .

\subsection{Structure of the network}

The full range of effects related to the delay in the construction of the Italian portion of the corridor has been identified and grouped into three clusters (namely, socio-economic aspects, environmental aspects and transport aspects). Moreover, the relationships among the elements have been established. Finally, all the elements in the clusters have been connected to the goal of the evaluation, that has been organized in an autonomous cluster. Figure 1 represents the decision network for the problem under examination. 


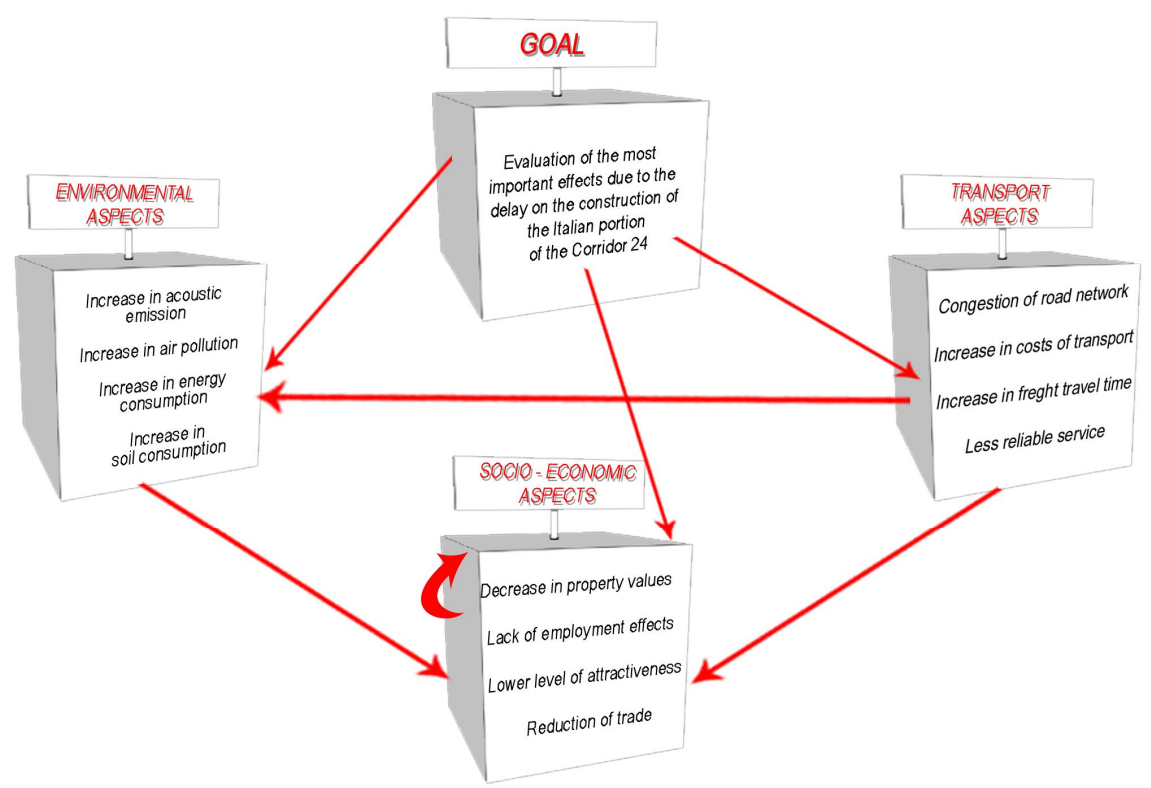

Figure 1. Decision network of the problem.

\subsection{Development of the model}

According to the ANP methodology, after having structured the decision network, the second step of the analysis consists in filling in the pairwise comparison matrices. It is important to highlight that there are two levels of pairwise comparisons in the ANP: the cluster level, which is more strategic, and the node level, which is more specialized. In pairwise comparisons, a ratio scale of 1-9, that is the Saaty's fundamental scale, is used to compare any two elements. The main eigenvector of each pairwise comparison matrix represents the synthesis of the numerical judgements established at each level of the network (Saaty, 1980). In the present application all the calculations have been implemented using the Super Decision software (www.superdecision.com).

Considering the pairwise comparison at the clusters level, the generated questions were of the type:

- Among the "Critical issues due to the delay in the realization of the Italian portion of CODE24", which of this two aspects do you think is more important and how much more?

\begin{tabular}{|c|c|c|c|c|c|c|c|c|c|c|c|c|c|c|c|c|c|c|}
\hline $\begin{array}{c}\text { Environmental } \\
\text { Aspects }\end{array}$ & 9 & 8 & 7 & 6 & 5 & 4 & 3 & 2 & 1 & 2 & 3 & 4 & 5 & 6 & 7 & 8 & 9 & $\begin{array}{c}\text { Socio-economic } \\
\text { Aspects }\end{array}$ \\
\hline
\end{tabular}

In this context, the weight that has been assigned to the socio-economic aspects reflects the economic expectations attributed to the construction of the corridor, such as the fear of becoming peripheral in the European context or the decrease in the capacity of attracting new economic activities; these expectations are considered much more important than the environmental issues.

Considering the pairwise comparison at the nodes level, the generated questions are of the type:

- With reference to the environmental aspects, among the "Critical issues due to the delay in the realization of the Italian portion of CODE24", which of this two elements do you think is more important and how much more?

\begin{tabular}{|c|c|c|c|c|c|c|c|c|c|c|c|c|c|c|c|c|c|c|}
\hline $\begin{array}{c}\text { Increase in acoustic } \\
\text { emissions }\end{array}$ & 9 & 8 & 7 & 6 & 5 & 4 & 3 & 2 & 1 & 2 & 3 & 4 & 5 & 6 & 7 & 8 & 9 & $\begin{array}{c}\text { Increase in air } \\
\text { pollution }\end{array}$ \\
\hline
\end{tabular}

The weight that has been given to the air pollution reveals the general opinion that considers the atmospheric quality more important than the acoustic one, even if, according to the sector literature, the increase in acoustic emissions can be seen as the cause of the main social costs due to the presence of a transport infrastructure. 


\subsection{Final results}

From the cluster level comparison it is possible to derive the cluster matrix, which represent the importance of the general aspects of the decision problem (Table 1). In the case under examination, the socio-economic aspects were given the highest importance $(0,649)$, followed by the transport aspects $(0,280)$ and finally by the environmental aspects $(0,071)$.

Table 1. Cluster matrix.

\begin{tabular}{|c|c|c|c|c|}
\hline & Goal & Environmental Aspects & Socio-economic Aspects & Transport Aspects \\
\hline Goal & 0,000 & 0,000 & 0,000 & 0,000 \\
\hline Environmental Aspects & 0,071 & 0,000 & 0,000 & 0,152 \\
\hline Socio-economic Aspects & 0,649 & 1,000 & 1,000 & 0,606 \\
\hline Transport Aspects & 0,280 & 0,000 & 0,000 & 0,242 \\
\hline
\end{tabular}

The totality of the eigenvectors that are derived from the pairwise comparison matrixes of the elements of the model forms the unweighted supermatrix (Table 2). The abbreviations in this table refer to Figure 2.

Table 2. Unweighted supermatrix.

\begin{tabular}{|c|c|c|c|c|c|c|c|c|c|c|c|c|c|c|}
\hline & & \multirow{2}{*}{$\begin{array}{c}\text { Goal } \\
\text { G }\end{array}$} & \multicolumn{4}{|c|}{ Environmental Aspects } & \multicolumn{4}{|c|}{ Socio-economic Aspects } & \multicolumn{4}{|c|}{ Transport Aspects } \\
\hline & & & E1 & E2 & E3 & $\mathrm{E} 4$ & S1 & S2 & S3 & S4 & $\mathrm{T} 1$ & $\mathrm{~T} 2$ & T3 & $\mathrm{T} 4$ \\
\hline Goal & $\mathrm{G}$ & 0,000 & 0,000 & 0,000 & 0,000 & 0,000 & 0,000 & 0,000 & 0,000 & 0,000 & 0,000 & 0,000 & 0,000 & 0,000 \\
\hline \multirow{4}{*}{$\begin{array}{l}\text { Environmental } \\
\text { Aspects }\end{array}$} & E1 & 0,083 & 0,000 & 0,000 & 0,000 & 0,000 & 0,000 & 0,000 & 0,000 & 0,000 & 0,100 & 0,000 & 0,000 & 0,000 \\
\hline & E2 & 0,225 & 0,000 & 0,000 & 0,000 & 0,000 & 0,000 & 0,000 & 0,000 & 0,000 & 0,225 & 0,000 & 0,000 & 0,000 \\
\hline & E3 & 0,619 & 0,000 & 0,000 & 0,000 & 0,000 & 0,000 & 0,000 & 0,000 & 0,000 & 0,675 & 0,000 & 0,000 & 0,000 \\
\hline & E4 & 0,073 & 0,000 & 0,000 & 0,000 & 0,000 & 0,000 & 0,000 & 0,000 & 0,000 & 0,000 & 0,000 & 0,000 & 0,000 \\
\hline \multirow{4}{*}{$\begin{array}{l}\text { Socio- } \\
\text { economic } \\
\text { Aspects }\end{array}$} & S1 & 0,054 & 0,000 & 1,000 & 0,000 & 0,000 & 0,000 & 0,000 & 0,000 & 0,000 & 0,166 & 0,000 & 0,000 & 0,000 \\
\hline & S2 & 0,168 & 0,000 & 0,000 & 0,000 & 0,000 & 0,000 & 0,000 & 0,000 & 0,000 & 0,000 & 0,000 & 0,000 & 0,000 \\
\hline & S3 & 0,389 & 0,000 & 0,000 & 0,000 & 0,000 & 0,000 & 0,000 & 0,000 & 1,000 & 0,834 & 0,750 & 0,750 & 0,000 \\
\hline & S4 & 0,389 & 0,000 & 0,000 & 0,000 & 0,000 & 0,000 & 0,000 & 0,000 & 0,000 & 0,000 & 0,250 & 0,250 & 1,000 \\
\hline \multirow{4}{*}{$\begin{array}{l}\text { Transport } \\
\text { Aspects }\end{array}$} & $\mathrm{T} 1$ & 0,304 & 0,000 & 0,000 & 0,000 & 0,000 & 0,000 & 0,000 & 0,000 & 0,000 & 0,000 & 0,000 & 0,080 & 0,000 \\
\hline & $\mathrm{T} 2$ & 0,082 & 0,000 & 0,000 & 0,000 & 0,000 & 0,000 & 0,000 & 0,000 & 0,000 & 0,000 & 0,000 & 0,732 & 0,000 \\
\hline & $\mathrm{T} 3$ & 0,192 & 0,000 & 0,000 & 0,000 & 0,000 & 0,000 & 0,000 & 0,000 & 0,000 & 0,000 & 0,000 & 0,000 & 0,000 \\
\hline & $\mathrm{T} 4$ & 0,422 & 0,000 & 0,000 & 0,000 & 0,000 & 0,000 & 0,000 & 0,000 & 0,000 & 0,000 & 0,000 & 0,188 & 0,000 \\
\hline
\end{tabular}

The cluster matrix is then applied to the unweighted supermatrix as a cluster weight and the result is the weighted supermatrix. Finally, the weighted supermatrix is raised to a limiting power in order to converge and to obtain a long-term stable set of weights that represents the final priority vector (Figure 2).

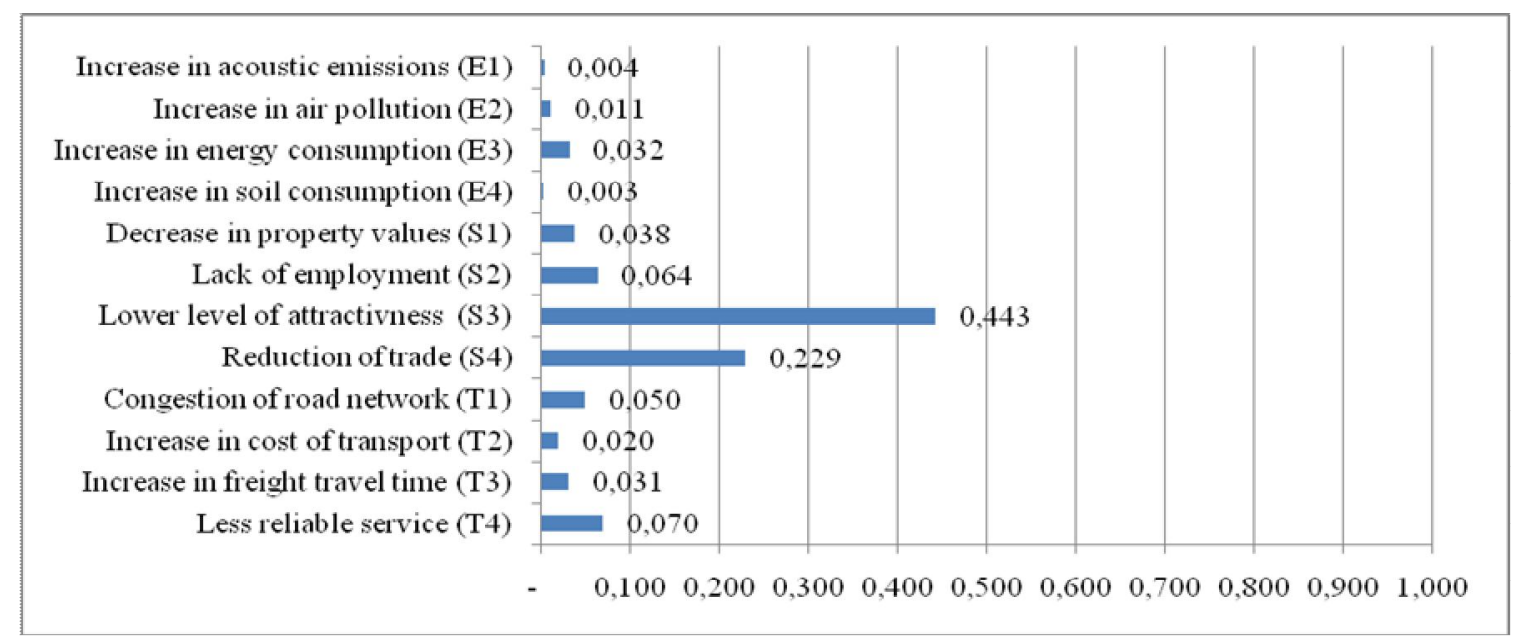

Figure 2. Final priority vector of the elements of the model. 


\section{Discussion of the results and conclusions}

The results of the ANP model coming from the priority vector of Figure 2 highlight some interesting findings that can be summarized as follows. The most important effect that the delay in the realization of the corridor could produce refers to the "lower level of attractiveness" element $(0,443)$, which belongs to the "Socio-economic aspects" cluster; this effect is approximately as important as all the other elements together. The second effect in the priority list is the "reduction of trade" element $(0,229)$ in the "Socioeconomic aspects" cluster . It is possible to say that the two aforementioned elements are independent but strongly interacting in determining the potential threats on the territorial system. The third element in order of importance refers to the "Less reliable service" element $(0,070)$ which is part of the "Transport aspects" cluster; it can be noticed that the reliability of service has been considered by the experts in the focus group more important than the freight travel time and the costs of transport. Mention should also be made to the fact that the elements belonging to the "Environmental aspects" cluster have been given a very low importance. This fact can be explained in two different ways: to start with, it is possible to suppose that the freight volume will decrease because of the segregation effect due to the absence of the corridor axis; secondly, the environmental effects are not a crucial point in the decision problem under examination because they would be very high also in the case of the construction of the corridor, considering the presence of the high speed rail.

The aforementioned considerations put in evidence that the results of the technical focus group reflect the concerns of the overall political class about the role that Italy could play in the international context. In fact, even if the project under examination refers to a transport infrastructure, the most important effects that one could expect from the delay in the construction of the corridor have a socio-economic nature and are not related to transport aspects or spatial planning considerations.

With reference to the future development of the work, there are still a number of opportunities for expanding the study and for validating the obtained results. First, it would be of scientific interest to implement the ANP model on the whole corridor, considering the organization of different focus groups with all the partners of the Code24 project. Secondly, future research could explore the use of the fuzzy logic in the ANP technique in order to tolerate fuzzy judgements in the pairwise comparison process (Liu and Lai, 2009). Finally, the application of the ANP model could be enriched by specific visualization tools that are of great importance for presenting and communicating the results of the analysis to Decision Makers and the interest group.

\section{REFERENCES}

Bertolini, L. (2001). Territorializzazione delle infrastrutture nei Paesi Bassi. In: G. Dematteis \& F. Governa (a cura di), Contesti locali e grandi infrastrutture. Milano: Franco Angeli.

Bottero, M., \& Lami, I.M. (2010). Analytic Network Process and sustainable mobility: an application for the assessment of different scenarios. Journal of Urbanism, 3, 275 - 293.

Bottero, M., Lami, I.M., \& Lombardi, P. (2008). Analytic Network Process. La valutazione di scenari di trasformazione urbana e territoriale. Firenze: Alinea.

Lami, I.M., \& Staffelbach, L. (2008). Evaluating the urban redevelopment of railway sites: Zurich Central Station and surrounding areas. In: Proceedings of the Third Kuhmo-Nectar Conference - Transport and Urban Economics, 3-4 July 2008, Amsterdam.

Liu, K., \& Lai, J.K. (2009). Decision-support for environmental impact assessment: A hybrid approach using fuzzy logic and fuzzy analytic network process. Expert Systems with Applications, 36, 5119-5136.

Nekhay, O., Arriaza, M., \& Boerboom, L. (2009). Evaluation of soil erosion risk using Analytic Network Process and GIS: a case study from Spanish mountain olive plantations. Journal of Environmental Management. 90, 3091-3104.

Saaty, T.L. (1980). The Analytic Hierarchy Process. New York: McGraw Hill.

Saaty, T.L. (2005). Theory and Applications of the Analytic Network Process. Pittsburgh: RWS Publications.

Saaty, T.L. \& Vargas, L.G. (2006). Decision Making with the Analytic Network Process. New York: Springer Science. 